\title{
Direito humano à alimentação adequada: fome, desigualdade e pobreza como obstáculos para garantir direitos sociais
}

\author{
Human right to adequate food: hunger, \\ inequality and poverty as obstacles to \\ guaranteeing social rights
}

\author{
Odaleia Barbosa de Aguiara \\ (1) http://orcid.org/0000-0001-9951-042X \\ Susana Moreira Padrãoa \\ (D) http://orcid.org/0000-0001-5650-4679
}

\begin{abstract}
Resumo: Este ensaio tem como objetivo refletir sobre o direito humano à alimentação adequada, de forma universal e permanente, ante a pobreza e a desigualdade social. Expressa a dificuldade das sociedades para eliminar o espectro da fome. Argumenta-se que o direito humano à alimentação adequada dificilmente será materializado sem a superação da fome, da pobreza e da desigualdade social, fenômenos interdependentes e que se inter-relacionam, inerentes e necessários à sociabilidade capitalista.
\end{abstract}

Palavras-chaves: Direitos Humanos. Alimentação. Dieta Saudável. Iniquidade Social.

\begin{abstract}
This essay aims to reflect on the human right to proper food, in an universal and permanent way, in the face of poverty and social inequality. It expresses the difficulty of societies to eliminate the spectrum of starvation. It is argued that the human right to adequate food is unlikely to be materialized without overcoming hunger, poverty and social inequality, interdependent and interrelated phenomena, inherent and necessary to capitalist sociability.
\end{abstract}

Keywords: Human Rights. Feeding. Healthy Diet. Social Inequity. 


\section{Uma breve história dos direitos humanos}

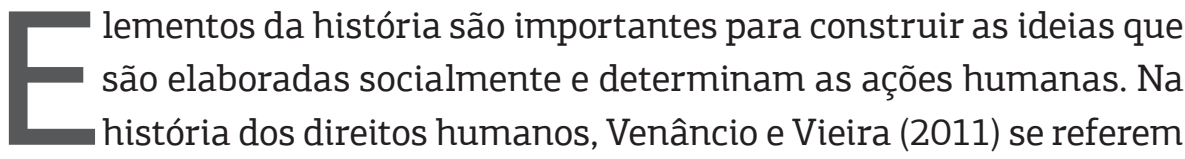

a uma peça de argila do Império Persa do século VI a.C., conhecida como Cilindro de Ciro, como registro da primeira carta de direitos humanos. Os direitos naturais eram velhos conhecidos dos gregos, da pólis surgiam todos os direitos e obrigações dos cidadãos, sua autoridade cobria todas as esferas do comportamento humano. Para os gregos clássicos, a liberdade se limitava ao direito de participar do governo da cidade, não se cogitava a possibilidade de se buscar objetivos pessoais, os direitos individuais eram desconhecidos (Gobbi, 2001).

Os direitos fundamentais e humanos foram sendo instituídos paulatinamente, com diferentes gradações e nuances até a Idade Média, nos sistemas absolutistas e feudais, dependentes de iniciativas locais, de reis e nobres, com a participação ou a conivência das igrejas. Lopes (2011), citando Bobbio (1992), descreve que embora possa parecer uma contradição aproximar os direitos humanos do Estado absoluto, foi esse contexto que possibilitou o desenvolvimento e a proclamação dos direitos do homem e do cidadão. Os direitos humanos eram resultado das lutas do povo pelo exercício real dos direitos idealmente concebidos, cujas razões, se quisermos compreendê-las, devem ser buscadas não mais na hipótese do estado de natureza, mas na realidade social da época e suas contradições.

O jurista Karel Vasak, conforme Franco Filho (2008), buscou demonstrar a evolução dos direitos humanos utilizando a expressão "gerações". Nesse processo, a "primeira geração" de direitos humanos reconhecidos se instituiu na fase de resistência aos poderes dos monarcas absolutistas, em decorrência do enfrentamento da burguesia como classe organizada, pela salvaguarda de direitos individuais básicos, tais como: da preservação de sua vida, de sua liberdade e da possibilidade de constituírem patrimônio, sem que este fosse confiscado pela exigência de tributos excessivos. 0 feudalismo em decadência começaria a dar lugar ao capitalismo. 
O marco dos direitos documentado foi a Declaração dos Direitos do Homem e do Cidadão, aprovada pela Assembleia Nacional Francesa em 26 de agosto de 1789. A Declaração proclama que todos os cidadãos devem ter garantidos os direitos de "liberdade, propriedade, segurança e resistência à opressão".

A "segunda geração" de direitos humanos nasce das lutas sociais que buscavam uma maior defesa das condições necessárias ao desenvolvimento pleno da humanidade, tendo como protagonistas as classes operárias, que surgiram e se organizaram como consequência da industrialização na Europa. Após a Segunda Guerra Mundial, o Estado assume o papel de administrador da sociedade e mediador de conflitos e, por meio de laços internacionais, se estabelece um núcleo fundamental de Direitos Humanos Internacionais, se intensificando o processo de internacionalização que se encerra na elaboração da Declaração Universal de Direitos Humanos (DUDH), de 1948, que pretende tornar universal o reconhecimento dos Direitos Humanos (Vieira Junior, 2015).

A partir da instituição da Declaração Universal de Direitos Humanos, se consolida a perspectiva de que os direitos humanos e as liberdades fundamentais devem ser providos e respeitados, bem como se consagra um consenso acerca dos valores a serem seguidos por todos os Estados, compreendidos como um conjunto de direitos universais. $\mathrm{O}$ processo de internacionalização pode ser creditado, em especial, à ideia de que a existência de um efetivo sistema de proteção internacional evitaria futuras violações, como as praticadas durante a Segunda Guerra, assim como possibilitaria a responsabilização internacional do Estado em caso de omissão, violação e falta de reparação (Corrêa; Oliveira, 2019).

As denominadas "terceira e quarta gerações" de direitos não possuem uma identificação clara dos agentes operadores, pois emergiram dos apelos de uma sociedade massificada, visando à preservação dos interesses coletivos ou difusos relacionados com a proteção do meio ambiente, a preservação do patrimônio histórico e cultural, a qualidade de vida nos ambientes urbano e rural, a tutela sobre a comunicação social, a bioética, 
a ampliação dos direitos políticos, a autodeterminação dos povos, o amplo acesso à informação e a preservação da privacidade. Alguns novos direitos são apenas os antigos adaptados às novas exigências do momento, isto é, alguns dos direitos fundamentais da primeira e da segunda geração estão sendo revitalizados e até mesmo ressignificados, obtendo importância, de modo especial, em face das novas formas de agressão que se expressam nas sociedades na atualidade (Soares, 2019).

Observa-se que a denominação apresentada, em relação às diferentes gerações de direitos, considera apenas sua sequência histórica, sem adentrar no mérito acerca da universalidade, indivisibilidade e interdependência entre os direitos, atributos consagrados pela Declaração dos Direitos Humanos de 1948. São declarados indivisíveis porque para a realização da cidadania e da dignidade humana a garantia de todos os direitos passa a ser igualmente imprescindível. Nesse sentido, os direitos não podem ser conflitantes, ou seja, a satisfação de um não pode justificar a não realização de outros. E ainda, são interdependentes e inter-relacionados, pois a materialização de um direito é requisito para o exercício dos demais. A declaração procurava associar direitos civis e políticos com direitos econômicos, sociais e culturais, "unificando o discurso Liberal e Social através da harmonização de Liberdade e Igualdade” (Daly, 2011, p. 4).

As normativas e as concertações, instituídas ao longo da história de reconhecimento dos direitos fundamentais e humanos, são frutos de longos processos de enfrentamento e conflitos na história da ampliação dos direitos dos povos, mas também avaliados como uma expressão da dinâmica colonial e imperialista do capitalismo, que busca, ainda hoje, manter, por meio desses instrumentos, países periféricos dependentes e subordinados à economia central e global (Soares, 2019). Não obstante, é possível identificar, a partir da metade do século passado, uma mudança na perspectiva do discurso dos direitos humanos, até então associado a uma tradição revolucionária, que passa a se afeiçoar, por meio de uma gramática de dignidade humana despolitizada e das políticas liberais, com o desenvolvimento capitalista e o próprio colonialismo (Corrêa; Oliveira, 2019). 
É necessário admitir que os avanços são inquestionáveis na instituição de diretos e que as lutas sociais pela concretização de políticas públicas que garantam a materialização e o reconhecimento continuam e se acirram. Assume-se, contudo, que os direitos humanos no mundo não se materializaram nem estão garantidos de forma universal e equânime, em especial o direito humano à alimentação adequada (DHAA) e em países periféricos, mesmo após a constituição de normativas e arcabouços legais e jurídicos, inclusive acordos internacionais que promoveram as condições de exigibilidade. Nesse aspecto, a avaliação de Corrêa e Oliveira (2019, p. 31) expressa uma posição que parece ser inequívoca: "Embora o processo de internacionalização dos direitos humanos seja concebido hegemonicamente como linear e consagrador de uma sociedade justa, a realidade invisibilizada - mas, perturbadora - desse processo é que no mundo atual a maioria esmagadora da população não é sujeito de direitos humanos, e sim meros objetos dos discursos pelos quais essa hegemonia se forma".

É forçoso reconhecer que a história das lutas sociais mais recentes, pela conquista de direitos, caminha passo a passo com a consolidação e a hegemonia do capitalismo e da sociedade de classes no mundo. Contraditória, a sociedade de classes ostenta direitos civis, sociais e políticos que se propõe a garantir e, dialeticamente, contribui com a manutenção da exploração estrutural promovida pelo capital. É peculiar que as lutas pelos direitos humanos se originem de condições exasperantes dos explorados e dos oprimidos, mas deságuem em alguma forma de distribuição de proteções, garantias, deveres e responsabilidades que são típicas do capitalismo, mas que não atentam contra o fundamental de sua sociabilidade (Mascaro, 2017).

Essas considerações não têm a intenção de esgotar nem simplificar o tema entendido como um grande desafio do mundo contemporâneo, que envolve dilemas insolúveis e inegociáveis, diferentes conceitos, categorias, abordagens políticas e ideológicas, além de análises teóricas que tratam de violações de direitos. A intenção é discutir o DHAA como um direito indivisível da situação de fome, pobreza e desigualdade social 
da população, embora possa parecer contraditório, como os direitos de liberdade e igualdade, por vezes, avaliados como divisíveis. E ainda reconhecer a luta por direitos legítima e como uma ferramenta de resistência cultural, política e social, em especial nas ditaduras e nos regimes fascistas (Soares, 2019).

Nessa direção, o objetivo deste ensaio é apreender a realidade social, reconstruindo o processo histórico de instituição dos direitos humanos, em especial do direto humano à alimentação adequada protagonizado, em grande medida, pelas classes sociais, sendo, portanto, resultado dinâmico da ação humana, além da possibilidade de sua materialização ante os fenômenos da fome, da pobreza e da desigualdade social como reflexos da realidade. $O$ direito humano à alimentação adequada é o objeto desta reflexão contextualizado no cenário do Brasil, percebido como parte de uma totalidade concreta integrante dos direitos humanos fundamentais, e cuja instituição é intrínseca às lutas e aos direitos conquistados pelos movimentos sociais, em permanente confronto com os interesses da acumulação capitalista. Nesse contexto, a fome, a pobreza e a desigualdade social são entendidas como expressões das contradições da sociedade capitalista que constituem a questão social. No sentido debatido por Iamamoto (1998, p. 27), "a questão social é apreendida como o conjunto das expressões das desigualdades da sociedade capitalista madura”.

\section{A origem e controvérsias do direito humano à alimentação adequada}

O acesso permanente aos alimentos é considerado uma condição fundamental para a manutenção da vida de todos os indivíduos. Nesse sentido, é inscrito como um direito inalienável e reivindicado como direito humano. Estar livre da fome e se alimentar regularmente com alimentos de qualidade são pressupostos para a materialização de outros direitos, portanto, indivisíveis e que afiançam a cidadania dos indivíduos (ONU, 1966). 
A história da alimentação no mundo foi marcada pelo medo da privação do alimento e pela desigualdade na distribuição da terra. 0 homem deixou a vida nômade, quando vivia em busca de alimentos e dependente dos caprichos da natureza, ainda na pré-história, quando começou a perceber a relação entre a terra e as sementes, e considerou que podia influenciar no processo de germinação, até então atribuído exclusivamente à natureza. A partir dessa descoberta, passou a viver em pequenas aldeias, iniciando, também, a atividade pastoril, sendo a alimentação consumida em pequenas quantidades e restrita a poucos alimentos (Ornellas, 2008).

Nas sociedades feudais, a produção agrícola desenvolvida pelos camponeses se expandiu, em grande medida, devido ao fato de a maior parte da colheita ser apropriada pelos titulares da terra, que pressionavam os agricultores a aumentarem seu cultivo. A produção agrícola passou a ser o principal suporte da alimentação, particularmente da população mais pobre, sendo o pão e o vinho os alimentos básicos do regime alimentar. Nessa época, as grandes crises de subsistência eram frequentes e sistemáticas, ocasionando colheitas restritas, casos em que a fome se estendia entre os próprios camponeses e às camadas populares urbanas. O século XIV ficou marcado por ter sido atravessado pelas duas piores situações de insuficiência de alimentos, até aquela data, que atingiram todo o velho continente, sendo o estado de penúria agravado pelo aparecimento da peste negra em 1348, que dizimou parcela significativa da população já enfraquecida pela fome (Riera-Melis, 2018).

Esse cenário persistiu e se agravou ao longo de seis séculos. A restrição aos direitos de utilização dos alimentos provenientes das florestas, as guerras religiosas e as grandes crises dos cereais foram alguns dos eventos que contribuíram para o agravamento e a propagação da fome. O desapossamento dos camponeses das propriedades rurais, apropriadas por nobres e burgueses, aos poucos transformou a agricultura de subsistência em uma agricultura de mercado, aumentando a subnutrição entre os camponeses que representavam quase $90 \%$ da população europeia. Apenas no final do século XIX, o problema começou a ser amenizado 
com a adoção de novas tecnologias e formas de cultivo, aliadas à revolução nos transportes dos insumos, à produção de novos alimentos, ao desenvolvimento de técnicas de conservação e da indústria alimentar, que impulsionariam a produção e o abastecimento de alimentos (Flandrin; Montanari, 2018). Em pouco tempo, no entanto, constrangimentos de ordem econômica limitaram o consumo alimentar dos trabalhadores ante a escassez e os altos preços praticados na comercialização dos alimentos. Os alimentos até então cultivados para a subsistência das famílias, no século seguinte, passam a ser uma mercadoria muito disputada e lucrativa.

A expressão "Direito Humano à Alimentação Adequada", em uma perspectiva ampliada e internacional, tem origem no Pacto Internacional dos Direitos Econômicos, Sociais e Culturais (PIDESC), adotado pela Assembleia Geral das Organizações das Nações Unidas (ONU) em dezembro de 1966. A inclusão do Direito Humano à Alimentação Adequada no PIDESC, após dez longos anos de sistemáticos debates, indica os conflitos para sua efetivação. $O$ documento final demorou a encontrar consenso entre os países que participavam de sua elaboração, uma vez que diferentes atores buscavam se apropriar e atribuir sentidos diversos ao DHAA. O Pacto entra em vigor na ordem internacional apenas em janeiro de 1976 e é ratificado pelo Brasil, por meio do Decreto Legislativo n. 226, de 12 de dezembro de 1991, quase três décadas após a adoção do Pacto (Leão, 2013). De acordo com Carvalho (2005, p. 10), os direitos sociais criam condições para que as sociedades se organizem no sentido de "reduzir os excessos de desigualdade produzidos pelo capitalismo e garantir um mínimo de bem-estar para todos. A ideia central em que se baseiam é a da justiça social".

Em 1999, o Comentário Geral 12, sobre o artigo 11 do PIDESC, explicita em detalhes o direito à alimentação, amenizando controvérsias quando argumenta que o direito à alimentação adequada se realiza quando todo homem, mulher, criança, sozinho ou em comunidade, têm acesso físico e econômico, ininterruptamente, a uma alimentação adequada ou aos meios necessários para sua obtenção (ONU, 1999). A questão que se examina 
aqui, em relação ao Comentário Geral 12, é que apesar de apontar elementos essenciais, estabelece previamente uma delimitação conceitual, apresentando uma proposição estática para o DHAA. Essa formulação não se coaduna com uma noção em movimento dialético e fruto de disputas políticas e conflitos econômicos e, portanto, em constante atualização, considerando os contextos e os tempos históricos (Corrêa; Oliveira, 2019). Um conceito em constante construção que traduzisse um movimento dinâmico seria mais condizente com a origem do processo de lutas que instituiu os diretos humanos ao longo da história, associado à tradição revolucionária, como avaliado e mencionado.

A sequência de proposições, normas e acordos internacionais instituídas, ao longo das últimas décadas, consolida como um direito humano fundamental o acesso permanente de todas as pessoas à alimentação adequada e de qualidade. Entretanto, mesmo com a aprovação desse conjunto de normativas, não se deve avaliar a materialização do DHAA de forma simplista e descontextualizada, considerando todos os indivíduos, a priori, como sujeitos de direito e, portanto, aptos a exercê-los, sem ponderar as reais e verdadeiras condições para sua efetivação (Corrêa; Oliveira, 2019).

\section{Desigualdade e pobreza no Brasil: a indivisibilidade e a interdependência da questão}

O Brasil, instado por pactos e normativas internacionais, aprovou uma série de instrumentos e políticas, nas duas últimas décadas, na perspectiva de garantir o DHAA. Em 2005, teve início um processo de discussão que promoveu a formulação de programas e a aprovação de leis definindo estratégias para a realização progressiva desse direito. Nesse sentido, foi homologada a Lei Orgânica de Segurança Alimentar e Nutricional (LOSAN), em 2006, considerada um passo importante nessa direção (ABRANDH, 2010).

Em 2010, já tardiamente, o DHAA passa a ser assegurado entre os direitos sociais da Constituição Federal do Brasil, com a aprovação da 
Emenda Constitucional n. 64. Entretanto, celebrados, em 2018, os 70 anos da Declaração Universal dos Direitos Humanos, o direito de estar livre da fome e da má nutrição e de ter acesso permanente à alimentação adequada não faz parte da realidade concreta de parcela significativa da população brasileira e mundial.

Segundo dados da Organização das Nações Unidas para a Alimentação e a Agricultura (FAO), em 2005, 852 milhões de pessoas sofriam de fome crônica no mundo e, desse total, 10\% estavam gravemente desnutridas nos países em desenvolvimento, como o Brasil. Segundo estimativas desse mesmo organismo, em 2010, eram 925 milhões, ou seja, quase $15 \%$ da população mundial que padecia de fome permanentemente (Leão, 2013). Relatório referente ao período de 2011-2013 indica um decréscimo no número de habitantes que apresentavam fome crônica no mundo, atingindo 842 milhões de pessoas. De acordo com a agência, esse resultado pode ser atribuído à recuperação econômica no mundo, com aumento da produção de alimentos, após a crise do capitalismo que se evidenciou a partir do ano de 2008 (FAO, 2013).

Nos anos seguintes, no entanto, a tendência de queda no número de pessoas atingidas pela fome é revertida, voltando a crescer. Os $815 \mathrm{mi}-$ lhões que viviam nessa situação em 2016 passam para quase 821 milhões como vítimas da fome, em 2017 (FAO et al., 2018). Os dados da FAO para o ano de 2019 continuam indicando uma tendência de crescimento, com o número ultrapassando os 821 milhões de pessoas, o que representa algo em torno de $11 \%$ da população mundial (FAO et al., 2019). Caso seja considerada a prevalência da insegurança alimentar moderada e grave, baseada na escala de insegurança alimentar, que passou a ser utilizada pelo órgão, o cenário é ainda mais crítico. A população em situação de insegurança alimentar, que representa a quantidade de pessoas que passam fome somadas àquelas sem acesso estável a alimentos suficientes para suprir sua necessidade alimentar durante o ano todo, é estimada pela FAO et al. (2019) em quase 2 bilhões de pessoas no mundo.

No Brasil, as altas taxas de desnutrição e subalimentação que prevaleceram no país, em décadas passadas, foram sendo reduzidas 
sistematicamente até o início dos anos de 2010. Dados da FAO indicam que, em 1990, mais de 20 milhões de brasileiros eram considerados desnutridos, número que em 2004 passou para 12,6 milhões e em 2007. para 7,4 milhões de brasileiros. Esse decréscimo contínuo possibilitou a saída do país do mapa da fome, divulgado pela ONU, indicando uma redução de $82,1 \%$, o que significa que o número de pessoas atingidas pela fome ficou abaixo de 5\% da população, em 2014 (Leão, 2013). No entanto, não se pode considerar que o problema tenha sido debelado. Os últimos dados divulgados, pela mesma organização, indicam que os números voltaram a crescer a partir de 2016. A FAO estima que em torno de 5,2 milhões de brasileiros estavam nessa situação em 2017, com uma tendência de crescimento, o que significa um aumento real em relação aos anos anteriores (FAO et al., 2018).

Dados divulgados pelo Instituto Brasileiro de Geografia e Estatística (IBGE, 2018) sobre o estado de pobreza no país, apresentados neste ensaio como um dos principais obstáculos ao acesso aos alimentos, que provoca fome e má nutrição na população, corroboram essa assertiva. A população em situação de pobreza, considerada aquela que vive com menos de $\mathrm{R} \$ 406,00$ por mês, passou de $25,7 \%$, em 2016 , para $26,5 \%$, em 2017, o que indica um acréscimo de dois milhões de pessoas que passaram a viver em situação de pobreza no país. Contingente que totalizava, naquele ano, 54,8 milhões de pessoas que, provavelmente, viviam em situação de insegurança alimentar ou atingidas pela fome (IBGE, 2018).

A Pesquisa Nacional por Amostra de Domicílios Contínua, realizada pelo IBGE (2019), divulgada em 2019, com dados referentes a 2018, confirma a tendência de crescimento da desigualdade e da pobreza no país. Os indicadores apontam que a renda média do $1 \%$ de trabalhadores mais ricos subiu de $\mathrm{R} \$ 25.593$ para $\mathrm{R} \$ 27.744$, uma alta de 8,4\%. Já se considerarmos os 5\% mais pobres da população, o rendimento do trabalho caiu 3,2\%. Neste último grupo de trabalhadores, o ganho médio mensal baixou de $\mathrm{R} \$ 158$ para $R \$ 153$. A mesma pesquisa indica, ainda, que a renda média do topo da pirâmide, em 2018, era 33,8 vezes maior que o rendimento médio da 
metade da população com menores rendimentos, cuja renda média mensal girava em torno de R $\$ 820$ (IBGE, 2019). Como o aumento do rendimento médio do $1 \%$ mais rico no país, o grupo de pouco mais de dois milhões de pessoas abocanhou $\mathrm{R} \$ 34,8$ bilhões de toda renda produzida no Brasil.

De acordo com Neri (2019), em 2015, a pobreza aumentou 19\% no país, representando 3,6 milhões de pessoas, já no período de 2015 a 2017 o crescimento atingiu 33\%. 0 aumento da fome e da pobreza no país está conexo ao crescimento da desigualdade social que, grosso modo, mede a distância entre as pessoas (Neri, 2019). O aumento da desigualdade sugere que as famílias estão cada vez mais distantes em relação às possibilidades de prover suas necessidades básicas. $\mathrm{O}$ estudo aponta que a desigualdade social manteve um aumento persistente nos últimos anos. Enquanto a renda da metade mais pobre da população, nos últimos sete anos, caiu cerca de $18 \%$, o 1\% mais rico teve um acréscimo de quase $10 \%$ no seu poder de compra. Essa concentração de renda desbanca, inclusive, o período histórico considerado, até então, o pico de desigualdade no país no ano de 1989 (Neri, 2019). Segundo o autor do estudo, o pesquisador Marcelo Neri, os dados têm como base a Pesquisa Nacional por Amostra de Domicílios Contínua de 2019 e o índice de Gini, que é um medidor global de desigualdade, portanto, passível de avaliações comparativas em relação a outros países.

O comportamento do índice de Gini para o período entre 2012 e 2019, apresentado pelo estudo (Neri, 2019), indica que a desigualdade decresce desde o primeiro trimestre de 2012, partindo de 0,6128, até o último trimestre de 2014, quando atingiu o seu nível mais baixo, 0,6003 nessa escala. A partir do primeiro trimestre de 2015 , volta a crescer atingindo seu pico, 0,6291, no primeiro trimestre de 2019. Os valores da escala de Gini vão de "O a 1", indicando que quanto mais o índice se aproxima de um (1), maior é a desigualdade. Como o intervalo na escala é circunscrito a um pequeno intervalo, os valores apontados são bastante significativos.

Os dados acerca da desigualdade, indicados pelo índice de Gini no estudo mencionado, são condizentes com o comportamento dos indicadores 
de pobreza analisados no mesmo estudo. A proporção de pobres em 2012 atinge 10,52\%, caindo para 8,38\% em 2014 e voltando a subir até alcançar 11,18\% em 2017, último ano apresentado na análise, com tendência à manutenção do crescimento. Os menores percentuais de pobreza coincidem com os menores indicadores de desigualdades, ou seja, o ano de 2014, quando o país saiu do Mapa da Fome divulgado pela ONU. Portanto, é possível correlacionar tais dados, indicando que a fome, a pobreza e a desigualdade social constituem um tripé que caminha, normalmente, na mesma direção, ainda que os acréscimos e os decréscimos não variem nos mesmos percentuais ou proporções.

Essa assertiva, embasada nos dados mencionados, aponta que a desigualdade social e a pobreza tendem a ser interdependentes e inter-relacionadas, além de promover a fome e obstaculizar o DHAA, em especial, quando atingem patamares insustentáveis como no final da década de 1980, pico da concentração de renda no país, e após 2014 quando a desigualdade volta a crescer. Importa ressaltar que as variações desses indicadores, que muitas vezes ocorrem de forma abrupta, coincidem como os grandes ciclos políticos vividos no país (Souza, 2018).

Minimizar as desigualdades sociais parece não ser tarefa fácil. A história das sociedades, até a contemporaneidade, tem sido marcada pela divisão das pessoas em grupos, caracterizada por diferentes formas de estratificação social, tendo como traço comum a desigualdade social. As classes sociais, como são concebidas atualmente, se corporificam nas sociedades burguesas, originárias das revoluções protagonizadas pela burguesia que superaram os Estados absolutistas, nos séculos XVIII e XIX. Consolidadas no mundo ocidental, apesar da origem revolucionária, essas sociedades não aboliram os diferentes grupos sociais característicos daquelas que as antecederam, mantendo a estratificação e a desigualdade social, modificando, apenas, as condições e as formas de opressão. A relação de produção estabelecida entre as classes nessas sociedades, ou seja, entre trabalhadores e capitalistas é marcada pelo antagonismo de interesses, pela subordinação, exploração e alienação, 
além do enriquecimento de uma classe em detrimento da pauperização de outra, fato que perpetua a concentração de renda, apropriada por uma ínfima parcela da população (Montaño; Duriguetto, 2011). Os dados que atualizam essas desigualdades são capturados em diferentes sociedades e períodos históricos e apresentados em diversos estudos (Piketty, 2014; Souza, 2018).

No Brasil, a história social conforma uma concentração de renda no topo da hierarquia, com caráter inercial, que expressa uma profunda desigualdade conectada à dinâmica política nacional. Importa ratificar que o percurso político e institucional no país ocorre combinado com a trajetória de altas concentrações de renda (Souza, 2018). Mesmo no período em que a desigualdade social aferida foi a mais baixa dos últimos anos, como no de 2014, esse fato se deu em função de políticas de inclusão e não de mecanismos de redistribuição de renda, ou seja, o impacto positivo não foi resultado de mudanças estruturais na política tributária, por exemplo, mas de políticas sociais de caráter compensatório e focalizado. A acanhada tributação direta sobre a renda e a propriedade não favorece uma política distributiva mais ampla e duradoura, com reflexos no médio e longo prazos. "Uma sociedade com uma pequena elite abastada e uma massa empobrecida tende a ser radicalmente diferente de uma sociedade em que a hierarquia de renda ou riqueza é relativamente achatada, ainda que ambas tenham a mesma renda per capita" (Souza, 2018, p. 23).

Considerando a colossal concentração de renda no país, as perspectivas para que o Brasil caminhe progressivamente para níveis de desigualdades menores são bastante limitadas. A quantidade significativa de recursos econômicos acumulados nas mãos de poucos lhes afiança um robusto capital político capaz de garantir uma posição privilegiada na direção da vida social. Mesmo que haja um compromisso político nessa direção, não há na história da economia mundial países que tenham partido de níveis de concentração tão acentuados e conseguido atingir índices menores, semelhantes aos de países desenvolvidos. Seria como "realizar um feito inédito" (Souza, 2018, p. 378). 
A situação de fome, que ainda persiste no Brasil e mundo, tende a oscilar conforme indicadores sociais e de desenvolvimento, que impactam os investimentos públicos, a oferta de serviços, o emprego, o acesso ao crédito e, obviamente, a pobreza e a desigualdade social, e estão associados às crises do capital. Se considerarmos que crises cíclicas são inerentes ao sistema capitalista e que a desigualdade social tem acompanhado toda a história das sociedades, então manteremos a fome como um espectro de difícil solução.

\section{Considerações finais}

A universalização do DHAA permanece, ainda, como uma meta importante da humanidade a ser atingida no século XXI. O conturbado e longo caminho para o reconhecimento do acesso permanente ao alimento como um direito fundamental e universal no mundo, bem como a dificuldade para sua materialização, indica que se trata de um tema complexo que envolve muitos interesses econômicos, políticos e sociais.

A perspectiva de que existe um caminho viável e exequível para materializar o DHAA, de forma permanente e equânime, mesmo na sociedade do capital, está colocada por parte dos movimentos sociais e ativistas dessa causa. Essa assertiva se expressa em posições que avaliam que a direção para avançar na garantia da Soberania Alimentar e da Segurança Alimentar e Nutricional, superando a fome e a realidade de violações ao Direito Humano à Alimentação Adequada, estaria na possibilidade de a sociedade civil, em um primeiro momento, exigir a instituição de políticas sociais de combate à fome e à pobreza, e, na etapa seguinte, na capacidade de a população e de os titulares de direitos, de posse dos instrumentos de exigibilidade disponíveis, exigirem a materialização e a garantia no atendimento aos direitos humanos. Portanto, os obstáculos apresentados poderiam ser superados pela capacidade de organização e enfrentamento da sociedade civil. 
Argumenta-se, no entanto, a necessidade de se identificar os obstáculos da realidade social, concretos, colocados por um sistema econômico que historicamente promove pobreza e desigualdade social, para que a população possa atingir uma posição menos vulnerável por meio de políticas públicas e sociais de Estado, mais duradouras e universais, que tenham como propósito imediato a distribuição de renda, a geração de emprego e a segurança alimentar e nutricional. A concretização do DHAA implica a ampliação da participação na riqueza coletiva, incorporando os direitos humanos, não em sua forma abstrata, que não garante o acesso universal e emancipador à riqueza socialmente construída. Avalia-se que é preciso reconhecer que os conteúdos vinculados aos direitos humanos refletem as contradições inerentes e necessárias à sociabilidade capitalista.

Considerando, entretanto, a trajetória de persistência da fome, da pobreza e das desigualdades sociais no mundo, conforme brevemente historicizado, mesmo após a sólida fundamentação e os mecanismos normativos e jurídicos instituídos, conquistados por meio de lutas sociais ininterruptas, conjectura-se sobre a possibilidade concreta de materialização dos direitos humanos, entre eles o DHAA, nos marcos da hegemonia do capital. Entende-se que as formas jurídicas não são, necessariamente, garantia de real efetividade e concretude dos direitos, independentemente de sua natureza. Seria um engano considerar que a garantia da cidadania ampla e irrestrita estaria assegurada pela legislação e pelo direito constitucional, mesmo com a participação ativa e engajada dos movimentos sociais.

Partindo-se dessa avaliação e da premissa apresentada, considera-se que o DHAA está intrinsecamente associado às expressões de fome, pobreza e desigualdade social. Avalia-se que não podemos retirar de nosso horizonte essa conquista, sem, contudo, guardar ilusões a respeito das contradições da sociedade do capital. As lutas sociais por direitos são premissas para se continuar avançando na perspectiva de limitar a exploração dos trabalhadores pelo capital, mesmo que por períodos 
restritos, promovendo melhores condições de vida e alguma justiça social. Considerando que os direitos não estão garantidos nas sociedades de classes, as lutas sociais são formas de enfrentamento necessárias e sempre urgentes.

\section{Referências}

AÇÃO BRASILEIRA PELA NUTRIÇÃO E DIREITOS HUMANOS (ABRANDH). Direito humano à alimentação adequada no contexto da segurança alimentar e nutricional. Brasília, 2010. Disponível em: https://fianbrasil.org.br/direito-humano-a-alimentacao-adequada-nocontexto-da-seguranca-alimentar-e-nutricional/. Acesso em: 10 jun. 2019.

BELLO, E. Cidadania, alienação e fetichismo constitucional. In: CONGRESSO NACIONAL DO CONPEDI, 18., 2009, São Paulo. Anais [...]. São Paulo, 2009.

CARVALHO, J. M. Cidadania no Brasil. Rio de Janeiro: Civilização Brasileira, 2005.

CORRÊA, L.; OLIVEIRA, L. C. Direito humano à alimentação adequada e a teoria crítica dos direitos humanos: um diálogo possível e necessário. In: CORREA, L. (ed.). Diálogos sobre direito humano à alimentação adequada. Juiz de Fora: Faculdade de Direito da Universidade Federal de Juiz de Fora, 2019. p. 26-40. Disponível em: https://actbr.org.br/ uploads/arquivos/livro-dhaa-versc3a3o-final.pdf. Acesso em: 3 jun. 2019.

DALY, E. Environmental human rights: paradigm of indivisibility. Widener Law School Legal Studies Research Paper, n. 11-05, 2011. Disponível em: https:/ssrn.com/ abstract=1743610 ou http://dx.doi.org/10.2139/ssrn.1743610. Acesso em: 3 jun. 2019.

FLANDRIN, J.-L.; MONTANARI, M. (ed.). História da alimentação. São Paulo: Estação Liberdade, 2018.

FOOD AGRICULTURE ORGANIZATION (FAO). The state of food insecurity in the world: the multiple dimensions of food security. Roma: FAO, 2013. Disponível em: http://www. fao.org/3/a-i3434e.pdf. Acesso em: 8 jan. 2020.

FOOD AGRICULTURE ORGANIZATION et al. O estado da segurança alimentar e nutrição no mundo 2018: fomentando a resiliência climática no domínio da segurança alimentar e nutrição. Roma: FAO, 2018. Disponível em: http://www.fao.org/3/I9553ES/i9553es.pdf. Acesso em: 10 jan. 2020.

FOOD AGRICULTURE ORGANIZATION et al. The state of food security and nutrition in the world 2019: safeguarding against economic slowdowns and downturns. Roma: FAO, 2019. Disponível em: http://www.fao.org/3/ca5162en/ca5162en.pdf. Acesso em: 10 jan. 2020. 
FRANCO FILHO, A. M. O desenvolvimento dos direitos humanos fundamentais numa perspectiva histórica. Direito e Democracia, v. 9, n. 2, p. 302-316, 2008.

GOBBI, H. J. Integração e liberdade: uma reflexão histórica. Revista Brasileira de Politica Internacional, v. 44, n. 1, p. 155-164, 2001.

HERKENHOFF, J. B. Gênese dos direitos humanos. [S. l.: s. n.], 2019. v. 1: História dos direitos humanos no mundo. Disponível em: http://www.dhnet.org.br/direitos/militantes/ herkenhoff/livro1/dhmundo/index.html\#7. Acesso em: 10 mar. 2019.

IAMAMOTO, M. O Serviço Social na contemporaneidade. São Paulo: Cortez, 1998.

INSTITUTO BRASILEIRO DE GEOGRAFIA E ESTATÍSTICA (IBGE). Síntese de indicadores sociais 2018: uma análise das condições de vida da população brasileira. Rio de Janeiro: IBGE, 2018. Disponível em: https://biblioteca.ibge.gov.br/visualizacao/livros/liv101629. pdf. Acesso em: 30 mar. 2020.

INSTITUTO BRASILEIRO DE GEOGRAFIA E ESTATÍSTICA (IBGE). Pesquisa nacional por amostra de domicílios contínua. Rio de Janeiro: IBGE, 2019. Disponível em: https:// www.ibge.gov.br/estatisticas/sociais/populacao/9171-pesquisa-nacional-por-amostrade-domicilios-continua-mensal.html?. Acesso em: 2 abr. 2020.

LEÃO, M. (ed.). O direito humano à alimentação adequada e o sistema nacional de segurança alimentar e nutricional. Brasília: ABRANDH, 2013. Disponível em: http:// www.mds.gov.br/webarquivos/publicacao/seguranca_alimentar/DHAA_SAN.pdf. Acesso em: 10 fev. 2019.

LOPES, A. M. d'Á. A era dos direitos de Bobbio. Entre a historicidade e a atemporalidade. Revista de Informação Legislativa, v. 48, n. 192, p. 7-19, 2011.

MASCARO, A. L. Direitos humanos: uma crítica marxista. Belo: Horizonte: Lua Nova, 2017.

MONTAÑO, C.; DURIGUETTO, M. L. Estado, classe e movimento social. 2. ed. São Paulo: Cortez, 2011.

NERI, M. A escalada da desigualdade: qual o impacto da crise sobre a distribuição de renda e a pobreza. Rio de Janeiro: FGV-Social, 2019. Disponível em: https://cps.fgv.br/ desigualdade. Acesso em: 31 mar. 2020.

ORGANIZAÇÃO DAS NAÇÕES UNIDAS (ONU). Resolução n. 2.200-A (XXI). Pacto Internacional dos Direitos Econômicos, Sociais e Culturais, dez. 1966.

ORGANIZAÇÃO DAS NAÇÕES UNIDAS (ONU). Comentário geral n. 12: o direito humano à alimentação adequada (art. 11). 1999. Disponível em: http://pfdc.pgr.mpf.mp.br/atuacao-econteudos-deapoio/publicacoes/alimentacao-adequada/Comentario\%20Geral\%20No\%20 12.pdf/view. Acesso em: 25 fev. 2020. 
ORNELLAS, L. H. A alimentação através dos tempos. Florianópolis: Editora da UFSC, 2008. PIKETTY, T. O capital no século XXI. Rio de Janeiro: Intrínseca, 2014.

RIERA-MELIS, A. Sociedade feudal e alimentação (século XII-XIII). In: FLANDRIN, J.-L.; MONTANARI, M. (ed.). História da alimentação. São Paulo: Estação Liberdade, 2018.

SOARES, L.E. Desmilitarização: segurança pública e direitos humanos. São Paulo: Boitempo, 2019.

SOUZA, P. H. G. F. Uma história de desigualdade: a concentração de renda entre ricos no Brasil, 1926-2013. São Paulo: Hucitec, 2018.

VENÂNCIO, M. A.; VIEIRA, G. D. O alvorecer de uma nova esperança: a ascensão do império persa e a libertação de Israel. RHEMA: Revista de Filosofia e Teologia, Juiz de Fora, v. 15, n. 48/49/50, p. 135-148, 2011.

VIEIRA JUNIOR, D. B. Teoria dos direitos fundamentais: evolução histórico-positiva, regras e princípios. Revista da Faculdade de Direito da UERJ, Rio de Janeiro, v. 28, p. 73-96, 2015.

\section{Agradecimentos}

Agradecemos à Lídice Barros Guerreiro pela leitura e pelas contribuições preciosas no início desta empreitada para a discussão de direitos humanos.

\section{Sobre as autoras}

Odaleia Barbosa de Aguiar - Doutora em Saúde Coletiva. Professora Associada do Departamento de Nutrição Aplicada.

E-mail: odaleia@uerj.br

Susana Moreira Padrão - Doutora em Serviço Social. Professora Adjunto do Departamento de Nutrição Aplicada.

E-mail: susanampadrao@gmail.com 